\title{
MEDIDAS DE RADIAÇÃO SOLAR E ÍNDICE DE ÁREA FOLIAR EM COBERTURAS VEGETAIS.
}

\author{
Elisa V. WANDELLI', Arí de O. MARQUES FILHO ${ }^{2}$
}

RESUMO - Um método de inversão de modelo físico de penetração de radiação solar em meio vegetal para estimar o índice de área foliar (IAF) é apresentado e testado neste trabalho para diferentes tipos de vegetação, como uma alternativa aos experimentos destrutivos, trabalhosos e de difícil implementação em coberturas florestais. Os dados de radiação foram obtidos durante o periodo seco de 1996 na Estação Experimental da Embrapa, (BR 174 - km 54, $2^{\circ} 31^{\prime}$ S, 60'01' O), Manaus, Brasil. O método produziu valores de IAF convergentes entre as classes de radiação adotadas, com estimativas mais estáveis para ocasiões em que há predomínio de luz difusa. A aplicação do procedimento de inversão deu origem aos seguintes valores de indice de área foliar e respectivos incrementos anuais: $3,5\left(0,35\right.$.ano $\left.{ }^{-1}\right)$ para a vegetação secundária intacta; $2,0\left(0,5\right.$.ano $\left.{ }^{-1}\right)$ para o sistema agroflorestal com palmeiras; e 1,6 $\left(0,4\right.$. ano $\left.^{-1}\right)$ para o sistema agroflorestal multiestratificado.

Palavras Chaves: Índice de área foliar, radiação solar, sistema agroflorestal, vegetação secundária, Amazônia.

\section{Solar Radiation Measurementes and Leaf Area Index (LAI) from Vegetal Covers.}

ABSTRACT - A method by which a physical model of the solar radiation transfer in a vegetal medium is inverted to estimate the leaf area index (LAI) for different types of vegetation is presented here, as an alternative to the destructive experiments, which are a hard task to implement on the vegetation covers. Radiation data were obtained during the dry season - 1996, at the Embrapa

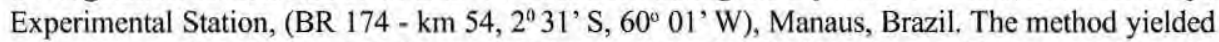
convergent values for the LAI between different adopted radiation classes with more stable estimates at time when there is a predominant diffuse radiation. The application of the inversion algorithm yields the following values for the leaf area index and respective annual foliage increments: $3.5\left(0.35 \mathrm{yr}^{-1}\right)$ for the intact secondary forest; $2.0\left(0.5 \mathrm{yr}^{-1}\right)$ for the palm agroforestry system; and $1.6\left(0.4 \mathrm{yr}^{-1}\right)$ for the multi-layer ones.

Key words: leaf area index, solar radiation, agroforestry system, secondary forest, Amazon.

\section{INTRODUÇÃO}

A dinâmica do indice de área foliar (IAF) de uma cobertura vegetal é resultante das respostas ecofisiológicas das plantas às condições químicas, fisicas e biológicas do solo; às condições do microclima (temperatura, umidade e radiação); às condições bióticas como herbivoria, competição e às interdependências desses fatores nos diferentes estágios sucessionais da vegetação.

$\mathrm{O}$ índice de área foliar tem forte relação direta com a produtividade primária e com a biomassa da vegetação. A importância desse indice nos intercâmbios de massa e energia no sistema solo-planta-atmosfera e as grandes dificuldades inerentes a determinação da biomassa vegetal favorecem e justificam o desenvolvimento de métodos para a estimativa do IAF. Contudo, os métodos diretos de medição de IAF, normalmente destrutivos e trabalhosos, necessitam da avaliação da área foliar total de volumes consideráveis da vegetação, como por exemplo o experimento de McWilliam

1 Empresa Brasileira de Pesquisa Agropecuária - EMBRAPA - Caixa Postal 319 - Manaus - AM

2 Instituto Nacional de Pesquisas da Amazônia - INPA - Caixa Postal 478 - Manaus - AM 
et al. (1993) que utilizaram uma área de $20 \mathrm{~m} \times 20 \mathrm{~m} \times$ a altura da cobertura vegetal. Essas dificuldades impulsionam o aparecimento e uso de métodos indiretos de fácil mensuração, baseados em medidas de penetração de radiação solar na vegetação (Welles \& Norman, 1991; Andrieu \& Baret, 1993). Além da praticidade, esses estudos sugerem que os métodos indiretos têm originado resultados similares aqueles produzidos por métodos diretos (Roberts et al., 1996).

Uma análise comparativa sobre métodos indiretos de determinação do índice de área foliar foi desenvolvida com dados experimentais por Honzák et al. (1996); medidas de radiação fotossinteticamente ativa (RFA) no interior da vegetação, contagem de manchas de radiação solar junto ao solo ("sunflecks") e fotografias hemisféricas, combinadas com modelos específicos de penetração de radiação na vegetação, compõem o conjunto de métodos indiretos que permitiram estimar o IAF para diferentes coberturas vegetais da Amazônia. A larga dispersão entre os valores individuais obtidos em um mesmo local e para uma mesma cobertura e a maior estabilidade dos resultados associados às fotografias hemisféricas do dossel são os traços marcantes desse estudo.

A penetração de radiação em uma cobertura vegetal depende das características dos elementos vegetais (tamanho, textura, espessura e orientação das folhas e dos galhos) e da estrutura da vegetação (altura das árvores, continuidade do dossel, densidade de indivíduos e densidade foliar, expressa pelo IAF). Estas variáveis são reunidas em modelos físicos de interação da radiação em meio vegetal (Nilson, 1971; Ross, 1981 e Myneni et al., 1989), que são apropriados para inversão e derivação do IAF quando desenvolvidos analiticamente.

Este trabalho busca ampliar as escassas informações sobre índice de área foliar de coberturas vegetais da Amazônia através de estudos de penetração de radiação solar com os seguintes objetivos :

1 - Testar metodologia de inversão de modelos de penetração de radiação em meio vegetal para estimar $o$ índice de área foliar.

2 - Estimar o índice de área foliar de vegetação secundária e de sistemas agroflorestais.

Pretende-se responder as seguintes questões:

$\mathrm{O}$ método desenvolvido permite obter índices de área foliar consistentes entre os diferentes horários (variações da inclinação do sol e das magnitudes de radiação) e representativos da cobertura vegetal?

O método desenvolvido incorpora distintas zonas de amostragem da cobertura na composição dos índices ?

Quanto maior é a proporção de luz difusa menor é a variabilidade em torno do IAF calculado?

Os sistemas agroflorestais têm incrementos médios anuais de área foliar superiores ao da vegetação secundária desenvolvida em área degradada?

\section{MATERIAL E MÉTODOS}

\section{A) Área de estudo}

Este estudo foi realizado na Estação Experimental do Distrito Agropecuário (Embrapa), localizado 
no $\mathrm{km} 54$ da Rodovia Manaus-Caracaraí (BR 174, $2^{\circ} 31^{\prime} \mathrm{S}, 60^{\circ} 01^{\prime} \mathrm{O}$ ), Amazonas, na área do projeto "Recuperação de áreas de pastagens abandonadas e degradadas através de sistemas agroflorestais". O solo é do tipo latossolo amarelo distrófico, textura muito argilosa.

As medidas de radiação foram realizadas em quatro coberturas vegetais com diferentes estruturas: duas vegetações secundárias e dois sistemas agroflorestais.

\section{Vegetação secundária intacta}

A vegetação secundária desenvolveu-se em uma área que permaneceu três anos com o solo descoberto através de três roçagens anuais e na época de estudo tinha dez anos de regeneração natural sem nenhum tipo de desbaste. As espécies dominantes por ordem de importância são: Vismia japurensis Reichardt, V. cayennensis (Jacq.) Press., V. guianensis (Aubl.) Choisy, Bellucia imperialis Saud. \& Cogn., B. glossularioides (L.) Triana, Laetia procera (Poeppig) Eichler e a semiperene Borreria verticillata (L.), G.F.W. Meyer, todas espécies tipicamente colonizadoras de solos degradados. A altura média desta vegetação é de 10 metros, com dossel contínuo, onde se concentra a maior parte da biomassa foliar. O subbosque apresenta baixa densidade foliar, principalmente devido a arquitetura das espécies do gênero Vismia, que perdem as folhas dos galhos sombreados no interior da vegetação.

\section{Vegetacão secundária manejada}

A vegetação secundária manejada tem a mesma composição florística que a da intacta, porém possui a cada quatro metros abertura no dossel em faixas contínuas de dois metros de largura para o plantio de mudas.

\section{Sistemas agroflorestais}

Os sistemas agroflorestais foram implantados em área de pastagem utilizada por quatro anos e abandonada à regeneração natural por três anos. Em 1992 após o corte e a queima da capoeira foram implantados sistemas agroflorestais. Durante os dois primeiros anos, enquanto as culturas perenes dos sistemas estavam em fase de desenvolvimento foram cultivadas espécies anuais como arroz, mandioca e feijão. No período de medição de radiação os sistemas agroflorestais estavam com quatro anos e com os seguintes componentes e arranjos espaciais (Souza et al., 1996; Wandelli et al., 1997):

\section{- Sistema agroflorestal com palmeiras (AS1)}

É um sistema agrossilvicultural formado por linhas de pupunha (Bactris gassipaes H.B.K.), plantada em 1992 para a produção de frutos e palmito, intercaladas com linhas das fruteiras, cupuaçu (Theobroma grandiflorum (Willd. ex Spreng.) Schum), plantada em 1992, e açaí (Euterpe oleracea Mart.), plantada em 1994. Em janeiro de 1995, após a primeira colheita de palmito (de cada três plantas de pupunheira duas destinam-se a produção de palmito), foi plantado mais um componente arbóreo, a madeireira capoeirão (Columbrina globulosa Perkins var. reitzii (M.C. Johnston) M.C. Johnston) (Fig. 1). 


\section{Sistema Agrossilvicultural 1 (AS 1)}

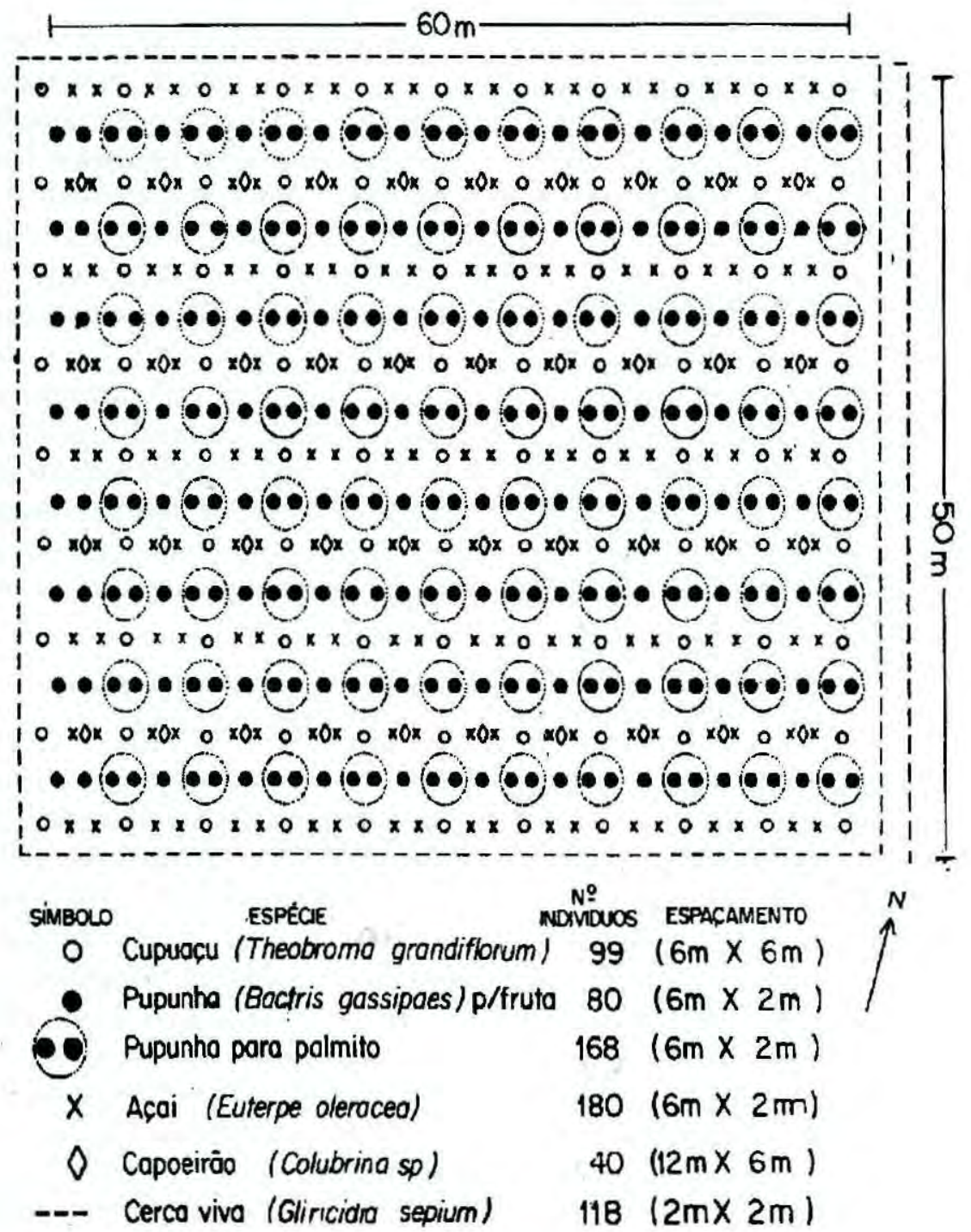

Figura 1. Arranjo espacial do sistema agroflorestal com palmeiras (AS1). 


\section{- Sistema agroflorestal} multiestratificado (AS2)

É um sistema agrossilvicultural formado pelas fruteiras cupuaçu (Theobroma grandiflorum) e ingá (Inga edulis Mart.), e pela essência florestal mogno (Swietenia macrophylla King.), plantadas em 1992; e pela fruteira araçá-boi (Eugenia stipitata Mc Vaugh) e a essência florestal exótica teca (Tectona grandis Linn), ambas plantadas em 1994. Neste sistema as medições de radiação foram realizadas somente na faixa central de $10 \mathrm{~m}$, onde os componentes vegetais têm cobertura mais contínua do que a das espécies das bordas (Fig. 2).
B) Desenvolvimento do modelo de obtenção de índice de área foliar

O fluxo de radiação solar no interior de uma cobertura vegetal é composto da soma de dois campos de radiação: o campo primário $\left(\mathrm{F}_{\text {prim }}\right)$ que incorpora apenas a radiação (direta e difusa) que atinge um dado plano horizontal no interior da vegetação sem interagir com os elementos vegetais; e o campo complementar $\left(\mathrm{F}_{\text {comp }}\right)$ que é um produto justamente da interação entre a radiação incidente e a vegetação, originando um espalhamento em todas as direções de parte da luz interceptada (Ross, 1981). Então, a uma dada altura (z) no interior

Sistema Agrossilvicultural 2 (AS 2)

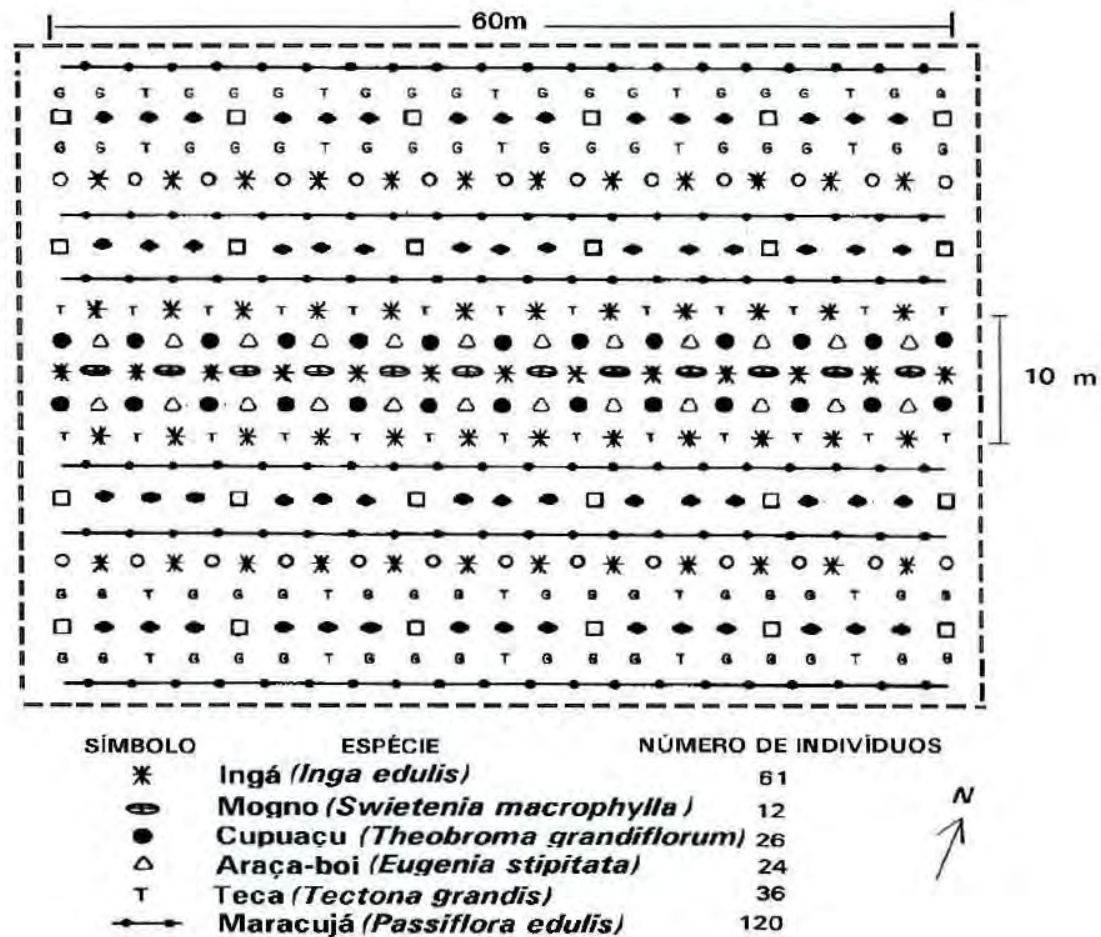

Figura 2. Arranjo espacial do sistema agroflorestal multiestratificado (AS2). 
da vegetação, o fluxo total de radiação $\left(F_{1}\right)$ e o fluxo total relativo $\left(\alpha_{\mathrm{r}}\right)$ referenciado a radiação no topo da cobertura podem ser descritos pelas seguintes equações, desenvolvidas especificamente para este estudo:

$\mathrm{F}_{\mathrm{t}}(\mathrm{A})=\mathrm{F}_{\text {prim }}(\mathrm{A})+\mathrm{F}_{\text {comp }}(\mathrm{A})$

$\alpha_{t}(\mathrm{~A})=\frac{\mathrm{F}_{t}(\mathrm{~A})}{\mathrm{F}_{\text {global }}(\mathrm{A}=0)}=\alpha_{\text {prim }}(\mathrm{A})+\alpha_{\text {comp }}(\mathrm{A})$

sendo:

$A(z)=\int_{z}^{h} a(z) d z$

onde,

F fluxo de radiação (W.m ${ }^{-2}$ )

A área foliar acumulada (adimensional)

a densidade de área foliar $\left(\mathrm{m}^{2} \cdot \mathrm{m}^{-3}\right)$

$\mathrm{z} \quad$ altura $(\mathrm{m})$

h altura da vegetação $(\mathrm{m})$

$\alpha \quad$ fluxo relativo de radiação, que é dado pela razão entre o fluxo medido em uma altura $\mathrm{z}$ da vegetação e o fluxo no topo.

No topo da vegetação, o fluxo total é composto pela radiação direta (proporção $\beta_{\mathrm{s}}$ ) caracterizada por uma direção única própria da posição do sol e pela radiação difusa (proporção $\beta_{\mathrm{d}}$ ) resultante do espalhamento da radiação solar na atmosfera terrestre e composta pela integração dos raios solares em todas as direções do hemisfério celeste. A soma dessas duas parcelas constitui a radiação global.

O comportamento da radiação solar no interior da vegetação é diferenciado para os diversos comprimentos de onda dos raios solares em função do espalhamento que eles sofrem ao interagirem com os elementos vegetais; o campo complementar deve portanto ser composto pela reunião dos espalhamentos parciais de diferentes zonas do espectro eletromagnético tratados separadamente. Baseado na equação 1 e para uma partição em "n" zonas o fluxo relativo de radiação $\left(\alpha_{1}\right)$ a uma "profundidade" A(z) da cobertura pode ser expresso pela equação 2 .

Nessa equação a radiação primária está associada aos dois primeiros termos do lado direito que representam a radiação direta $\left(\mathrm{F}_{\mathrm{s}}\right)$ e difusa $\left(\mathrm{F}_{\mathrm{d}}\right)$; a radiação complementar, última parte da equação, é representada pelos termos afetados pelo coeficiente de partição $\gamma_{k}\left(\Sigma \gamma_{k}=1\right)$. A partição adotada na presente versão desse modelo resume-se a duas zonas do espectro correspondentes às radiações fotossinteticamente ativa (RFA) e infra-

onde,

$$
\begin{array}{ll}
\alpha_{\mathrm{s}}(\mathrm{A})=\mathrm{F}_{\mathrm{s}}(\mathrm{A}) / \mathrm{F}_{\mathrm{s}}(\mathrm{A}=0) & \alpha_{\mathrm{d}}(\mathrm{A})=\mathrm{F}_{\mathrm{d}}(\mathrm{A}) / \mathrm{F}_{\mathrm{d}}(\mathrm{A}=0) \\
\alpha_{\mathrm{s} 1}(\mathrm{~A})=\mathrm{F}_{\mathrm{sl}}(\mathrm{A}) / \mathrm{F}_{\mathrm{s}}(\mathrm{A}=0) & \alpha_{\mathrm{d} 1}(\mathrm{~A})=\mathrm{F}_{\mathrm{d} 1}(\mathrm{~A}) / \mathrm{F}_{\mathrm{d}}(\mathrm{A}=0)
\end{array}
$$


vermelha (RIV) com coeficientes equivalentes $\left(\gamma_{1}=\gamma_{2}=0,5\right)$.

Os fluxos relativos de radiação direta e difusa primária $\left(\alpha_{\mathrm{s}}\right.$ e $\left.\alpha_{\mathrm{d}}\right)$ e os fluxos complementares descendentes em cada zona do espectro (RFA, RIV) são calculados pelas expressões seguintes (Abramowitz \& Stegun, 1970): (Marques Filho, 1992, 1997) definição ou medida dos parâmetros e funções que a compõem gera a função:

$$
\mathbf{A}=\mathbf{A}\left(\alpha_{t}\right)
$$

que será utilizada no presente estudo para o cálculo do indice de área foliar de coberturas vegetais.

\section{C) Medidas de radiação}

As medidas de radiação solar glo-

$$
\begin{aligned}
& \alpha_{s}(\mathrm{~A}(\mathrm{z}))=\mathrm{e}^{-\mathrm{K}(\theta \mathrm{s}) \mathrm{A}(\mathrm{z})} \\
& \alpha_{\mathrm{d}}[\mathrm{A}(\mathrm{z})]=\int_{0}^{\pi / 2} \mathrm{e}^{-\mathrm{K}(\theta) \mathrm{A}(\mathrm{z})} \cos \theta \cdot \operatorname{sen} \theta \cdot \mathrm{d} \theta \\
& \mathrm{F}_{1}(\mathrm{~A})=\mathrm{F}_{\mathrm{p} 1}(\mathrm{~A})-\frac{\Phi\left[\mu, \mathrm{r}\left(\mathrm{A}_{0}-\mathrm{A}\right)\right]}{\Phi\left[\mu, \mathrm{rA} \mathrm{A}_{0}\right]} \mathrm{F}_{\mathrm{p} 1}(0)-\frac{\Phi[1, \mathrm{rA}]}{\Phi\left[\mu, \mathrm{rA} \mathrm{A}_{0}\right]} \mathrm{F}_{\mathrm{p} 2}\left(\mathrm{~A}_{0}\right) \\
& \Phi[x, y]=x e^{y}-\left(x e^{y}\right)^{-1}
\end{aligned}
$$

onde,

$F_{1} \quad$ fluxo de radiação complementar descendente

$r, \mu$ parâmetros dependentes dos coeficientes de reflexão e transmissão dos elementos vegetais,

$K(\theta)$ coeficiente de extinção de luz $[=1 /(2 \cos \theta)]$ para a orientação aleatória dos elementos vegetais.

As funções $\mathrm{F}_{\mathrm{p1}}$ e $\mathrm{F}_{\mathrm{p} 2}$ surgem dos procedimentos de integração dos sistemas de equações diferenciais e são especificas aos termos primários de radiação direta e difusa. As formas adotadas no presente estudo são apropriadas para vegetação densa com distribuição espacial aleatória dos elementos vegetais. O campo de radiação complementar é também considerado independente das caracteristicas de reflexão da superficie do solo (albedo do solo negligenciado).

$\mathrm{A}$ inversão da equação 2 por meio de um algoritmo computacional e com a bal (comprimentos de onda entre $300 \mathrm{e}$ $4000 \mathrm{~nm}$ ) foram realizadas durante quatro semanas da estação seca de 1996, com um total de sete dias de observações para cada tipo de cobertura.

O sistema de medidas é composto por dois dispositivos eletrônicos de aquisição de dados sincronizáveis (datalogger 21X, Campbell Instruments) e sete sensores do tipo solarimetro tubular com dimensão de $2 \mathrm{~cm} \mathrm{x} 100 \mathrm{~cm}$ (Tube Solarimeter - Delta T).

A radiação externa foi medida em uma área aberta adjacente a cobertura 
vegetal por um solarímetro tubular e um solarímetro clássico (Kipp Solarimeter). Essa radiação é equivalente a radiação que atinge o topo da vegetação e foi utilizada no cálculo dos fluxos relativos.

Para medir a radiação que penetra no interior da vegetação instalou-se seis solarímetros tubulares a $40 \mathrm{~cm}$ do solo dispostos em intervalos de $1 \mathrm{~m}$. O dispositivo de aquisição de dados foi programado para fornecer médias individuais para cada sensor em intervalos de 20 minutos, compostas a partir de varreduras espaçadas de 10 segundos, coletando dados simultâneos nos sete pontos amostrais..

O sistema de aquisição de dados foi implementado na vegetação secundária intacta no período de $26 / 06$ / 96 a 03/07/96, na vegetação secundária manejada no periodo de $03 / 07 / 96$ a 10 / 07/96, no sistema agroflorestal com palmeiras no periodo de $10 / 07 / 96$ a $17 /$ 07/96, e no sistema agroflorestal multiestratificado no periodo final de 17/07/96 a 23/07/96.

Para ajudar a interpretação do padrão e da intensidade da radiação externa de cada dia e para se ter um referencial único da radiação solar acima da vegetação foi composta a curva de valores máximos medidos nos ciclos diurnos durante 0 período total de observações . Essa curva envoltória de radiação máxima que aparece nas figuras 3 a a 8 a permite inferir as condições gerais da atmosfera na evolução diurna e representa a referência básica para a separação em classes de radiações medidas em cada horário: I - 0 a $25 \%$; II - 25 a 50\%; III - 50 a $75 \%$; IV - 75 a $100 \%$ do valor máximo do período de observação.
Os valores dos parâmetros que aparecem nas equações 2 e 6 para as classes estabelecidas de radiação foram baseados em medidas e discussões apresentadas por Ross (1981) e Marques Filho (1997) e representam uma primeira aproximação na aplicação atual do modelo (Tab. 1).

Tabela 1. Parâmetros do modelo de radiação.

\begin{tabular}{|l|cccc|}
\hline Classes & I & II & III & IV \\
\hline $\begin{array}{l}\text { Radiação } \\
\text { direta } \beta_{\mathrm{S}}\end{array}$ & 0,1 & 0,3 & 0,5 & 0,7 \\
\hline $\begin{array}{l}\text { Radiação } \\
\text { difusa } \beta_{\mathrm{d}}\end{array}$ & 0,9 & 0,7 & 0,5 & 0,3 \\
\hline
\end{tabular}

\section{RESULTADOS E DISCUSSÃO}

Do conjunto de observações de radiação foram escolhidos alguns exemplos de cursos diurnos (Figs, 3 a 8 ) associados a condições atmosféricas distintas nos diferentes ambientes estudados, procurando-se evidenciar as transformações de padrões e magnitudes sofridas pela radiação no interior da vegetação.

Neste trabalho, os dados do solarímetro Kipp são apresentados como referência e controle das medidas dos tubos solarímetros. Entretanto, como o sensor tubular externo registrou dados idênticos aos do já conhecido e testado solarimetro de cúpula esférica (Figs. 3a a 7a), obteve-se confiança nos solarimetros tubulares e os dados utilizados para o cálculo do IAF referem-se somente a este tipo de sensor.

A figura 3 ilustra a radiação medida no dia 28/06/96 em área externa a pleno sol próxima à cobertura (a) e 
no interior de vegetação secundária intacta (b). A radiação externa é bem inferior à curva de valores máximos na parte da manhã, situação caracteristica de céu parcialmente encoberto; na parte da tarde os niveis de radiação elevam-se acentuadamente, persistindo entretanto flutuações associadas aos movimentos de nuvens (Fig. 3a). A radiação medida junto ao solo no interior da vegetação apresenta o mesmo padrão da radiação externa com exceção de um único tubo que forneceu os valores mais discrepantes no período de 13:00 às 15:00 horas. No período de predominância da radiação difusa (até 12 horas) os tubos dispostos no interior da vegetação apresentaram valores concordantes, entretanto no período de maior radiação direta (12:00 às 16:00 horas) houve uma discrepância entre eles (Fig. 3b).

$\mathrm{Na}$ vegetação secundária intacta em dia de céu totalmente encoberto, houve uma forte relação entre a radiação externa (Fig. 4a) e a radiação medida no interior da vegetação (Fig. $4 \mathrm{~b}$ ). A variabilidade das medidas dos tubos dispostos no interior da vegetação é pequena e os padrões são similares. O campo externo de radiação em condições de céu encoberto tende a ser homogêneo. Essa característica do campo pode ser modificada após a interação da radiação no meio vegetal em função das irregularidades próprias da vegetação: densidade horizontal de indivíduos, aberturas do dossel e distribuição vertical dos elementos vegetais. Em uma situação de limite, a persistência da homogeneidade do campo de radiação no interior da vegetação é condição necessária para caracterizar a homogeneidade do meio. Então a pequena discrepância entre as medidas é indicativo de cobertura vegetal homogênea.

$\mathrm{Na}$ vegetação secundária manejada com abertura de faixas de 2 metros em um dia de céu extremamente limpo com apenas uma pequena passagem de nuvens por volta de meio dia, não houve relação entre os padrões da radiação externa (Fig. 5a) e da radiação interna (Fig. 5b) dos tubos solarímetros; no interior da vegetação houve uma grande desigualdade entre os padrões e medidas individuais. Estes fatos são atribuídos a configuração do manejo imposto a vegetação. Este manejo de aberturas em faixas faz com que a penetração de radiação seja máxima no período de maior insolação (10:00 - 16:00h), em particular nas condições atuais que determinam uma clara assimetria de exposição, com uma maior incidência no período vespertino.

No sistema agroflorestal com palmeiras, mesmo em dias de céu limpo, houve uma relação direta entre o padrão da radiação que atingiu o topo da cobertura vegetal (Fig. 6a) e a que penetrou no interior da vegetação (Fig. 6b). Essa relação indica que a cobertura vegetal desse sistema é homogênea. Nos horários de maior incidência de radiação direta (9:00 - 11:00; 12:00 - 13:30), apesar dos padrões similares, existe uma grande discrepância entre as curvas de cada tubo sularimetro se comparadas aos valores do período de radiação difusa. A coincidência não só de padrões mas 
também de valores dos tubos solarimetros em períodos de radiação difusa demonstra que esta é mais apropriada para inferir características de cobertura vegetal, pois nela não existe a influência preferencial de um ângulo de incidência (ausência de radiação direta).

No sistema agroflorestal multiestratificado em dia de céu limpo houve uma baixa relação entre a radiação externa (Fig. 7a) e a radiação medida no interior da vegetação. Entretanto a curva de radiação interna média é bastante similar a radiação externa (Fig. 7b). Existe ainda uma diferença entre os valores de radiação dos tubos solarimetros dispostos no interior da vegetação. Esta falta de relação encontrada em dias de céu limpo é esperada nesta cobertura não contínua.

Nos dias de luz difusa ocorreu uma estreita relação entre os padrões de radiação externa (Fig. 8a) e interna (Fig. 8b) mantida porém a discrepância entre os tubos individuais, corroborando a idéia anterior de vegetação heterogênea. Devido a falha do solarímetro Kipp que media a radiacão externa, a curva apresentada corresponde a dados da estação automática instalada a aproximadamente $15 \mathrm{~km}$ do local de estudo e por isso ocorreu uma pequena defasagem temporal entre os picos das curvas de radiação externa e interna. É interessante observar a extrema concordância qualitativa entre as curvas dos solarímetros colocados no interior da vegetação, uma evidência a mais da extrema homogeneidade qualitativa do campo de radiação mesmo no interior de coberturas menos densas para os dias em que predominam condições de luz difusa.

Os exemplos apresentados acima representam a radiação solar medida no interior de coberturas vegetais como resultante da combinação de características e variabilidade do campo da própria radiação confrontadas às propriedades físicas (reflexão, transmissão, tamanho dos elementos individuais) e às diferentes estruturas de vegetação.

Em uma vegetação densa, com indice de área foliar acima de 3 , as dificuldades amostrais para estabelecer medidas representativas da radiação em seu interior, junto ao solo, são reduzidas em função de uma tendência para a homogeneização do campo de radiação. Parece natural supor-se um processo crescente de homogeneização quando se passa de condições atmosféricas sem cobertura de nuvens (céu limpo) em que a radiação direta externa à vegetação é um fator gerador de heterogeneidade, para a condição limite de céu totalmente encoberto, que determina um campo externo homogêneo composto somente de radiação difusa.

As respostas da vegetação com suas irregularidades específicas à essas duas situações extremas na interceptação e espalhamento da radiação determinam o domínio e a complexidade do método a ser utilizado, passando de um modelo físico mais geral com descrições específicas das componentes de radiação direta e difusa para um modelo particular puramente difuso.

$\mathrm{O}$ estabelecimento de classes de 

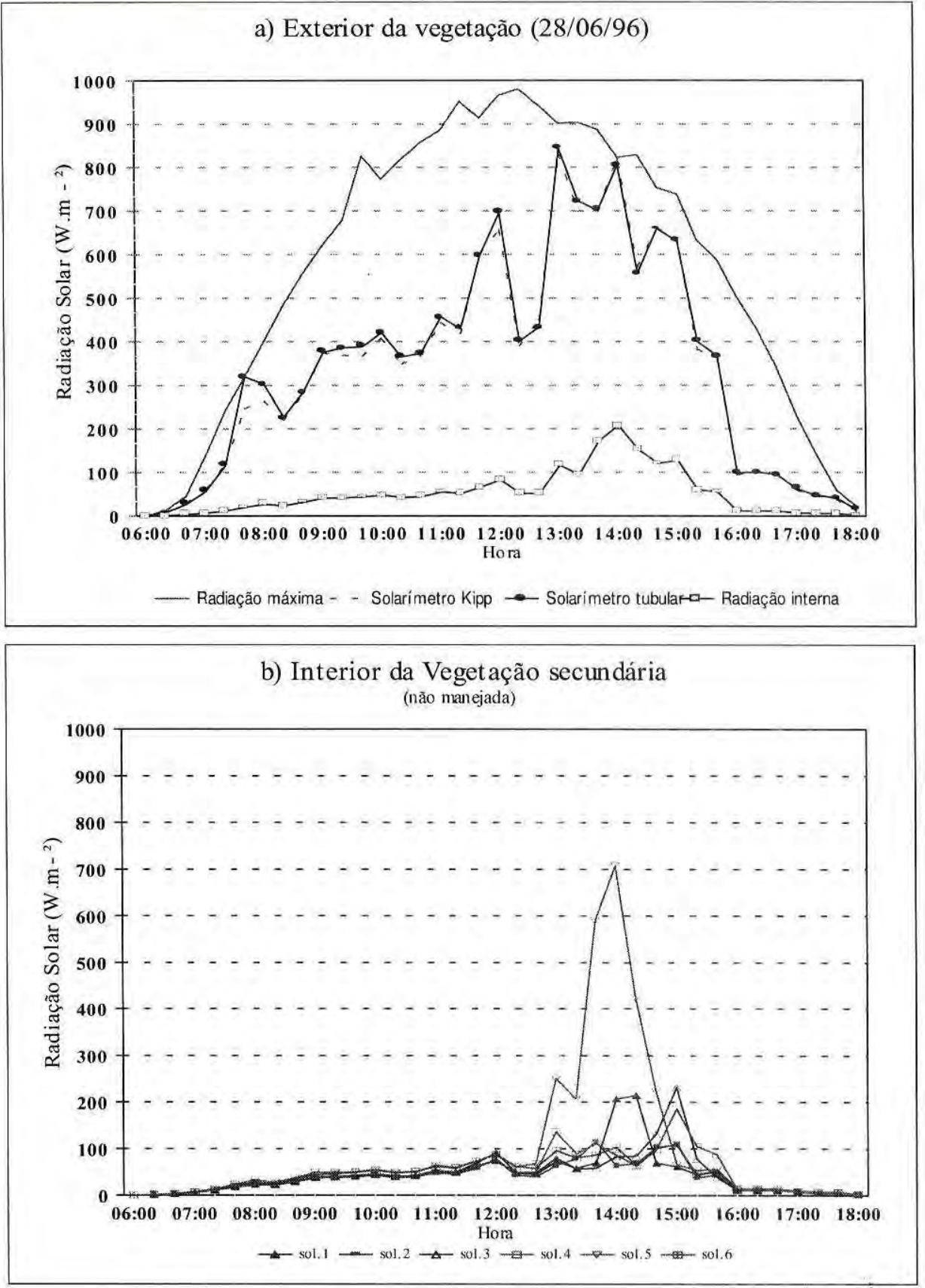

Figura 3. Exemplo comparativo de cursos diurnos de radiação solar em dia de céu claro: a) área externa, equivalente a radiação no topo da vegetação; b) interior de vegetação secundária intacta em que cada curva representa medidas de um solarímetro tubular. A radiação interna mostrada na parte (a) da figura representa a média das curvas da parte (b). 

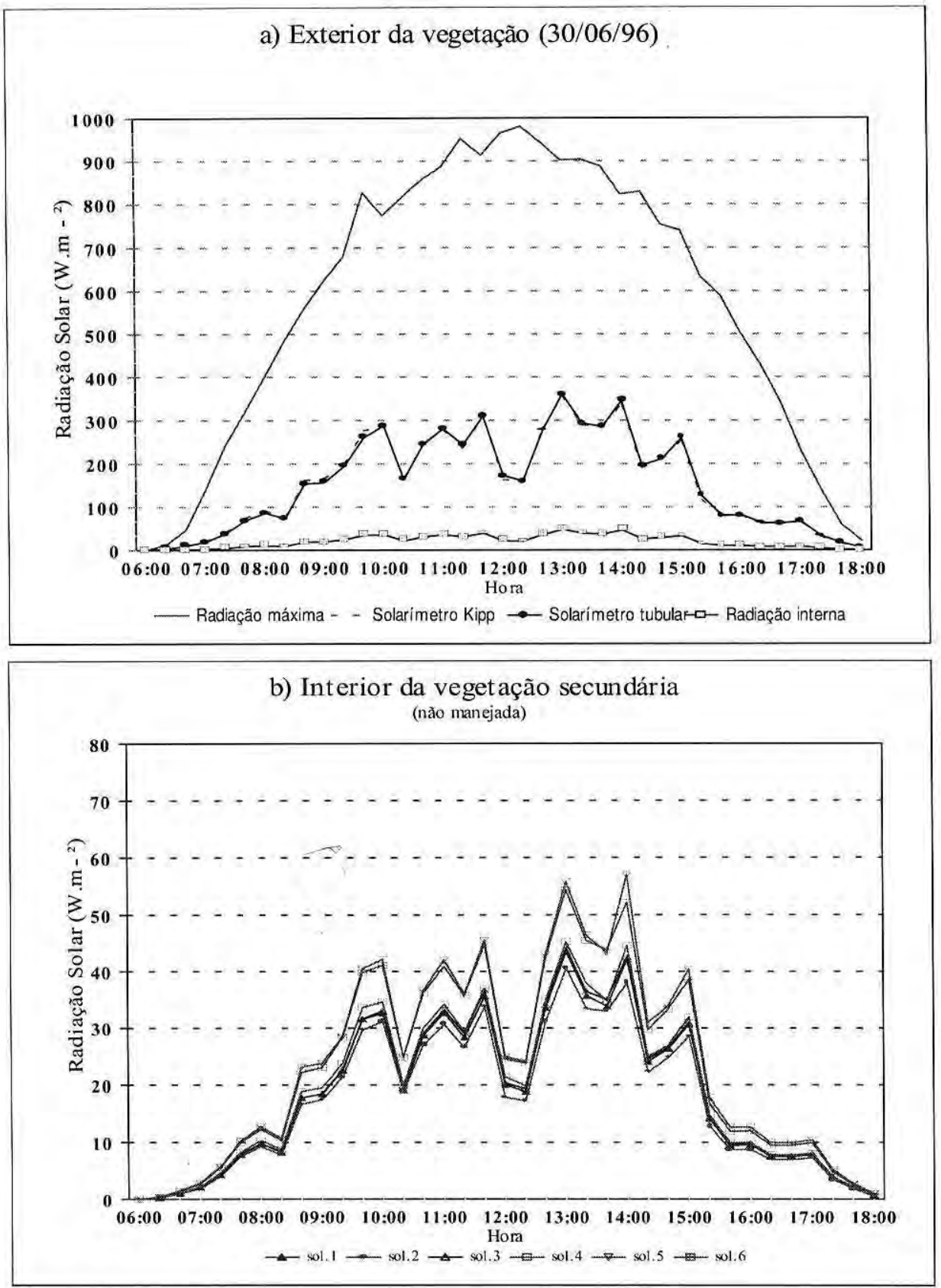

Figura 4. Exemplo comparativo de cursos diurnos de radiação solar em dia nublado: (a) área externa representando a radiação no topo da vegetação; b) interior da vegetação secundária intacta em que cada curva representa medidas de um solarimetro tubular. A radiação interna mostrada na parte (a) da figura representa a média das curvas da parte (b). 

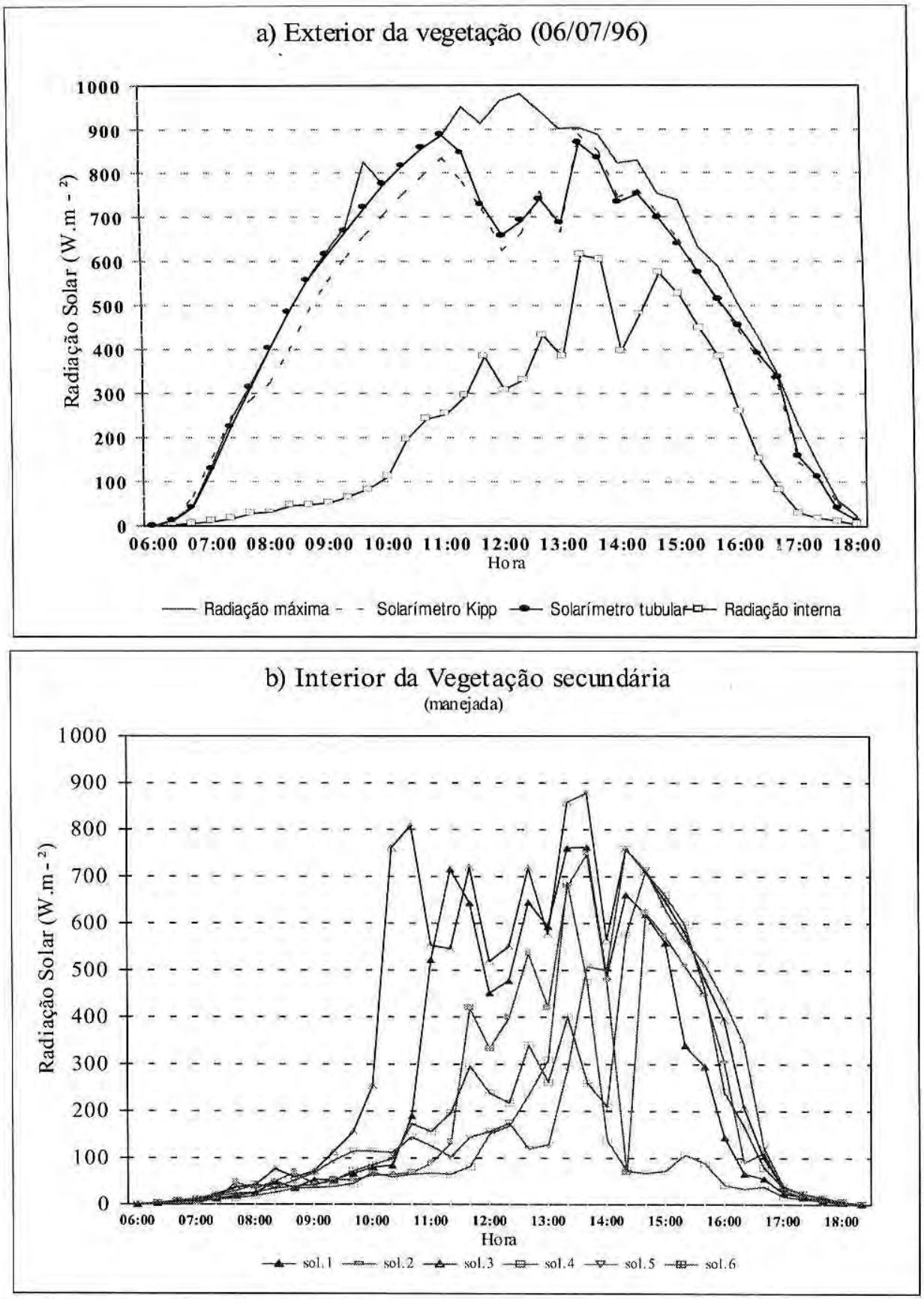

Figura 5. Exemplo comparativo de cursos diurnos de radiação solar em dia de céu claro: a) área externa representando a radiação no topo da vegetação; b) interior de vegetação secundária manejada com aberturas de faixas de $2 \mathrm{~m}$ de largura, cada curva é associada às medições de um solarímetro tubular. A radiação interna mostrada na parte (a) da figura representa a média das curvas da parte (b). 

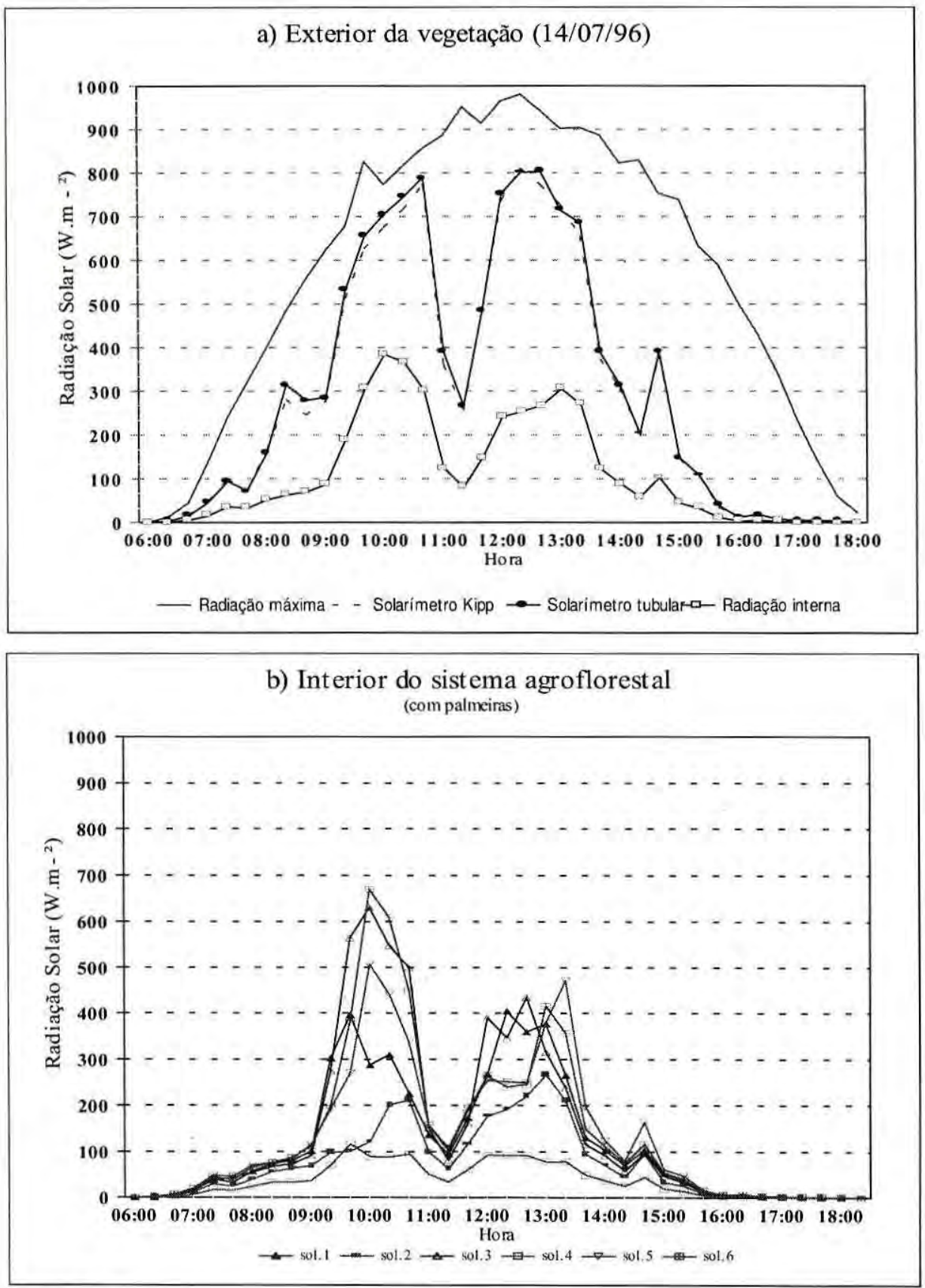

Figura 6. Exemplo comparativo de cursos diurnos de radiação solar em dia de céu claro, com nuvens somente durante o meio dia: a) área externa, representando a radiação no topo da vegetação; b) interior do sistema agroflorestal com dominio de palmeiras em que cada curva representa medidas de um solarímetro tubular. A radiação interna mostrada na parte (a) da figura representa a média das curvas da parte (b). 

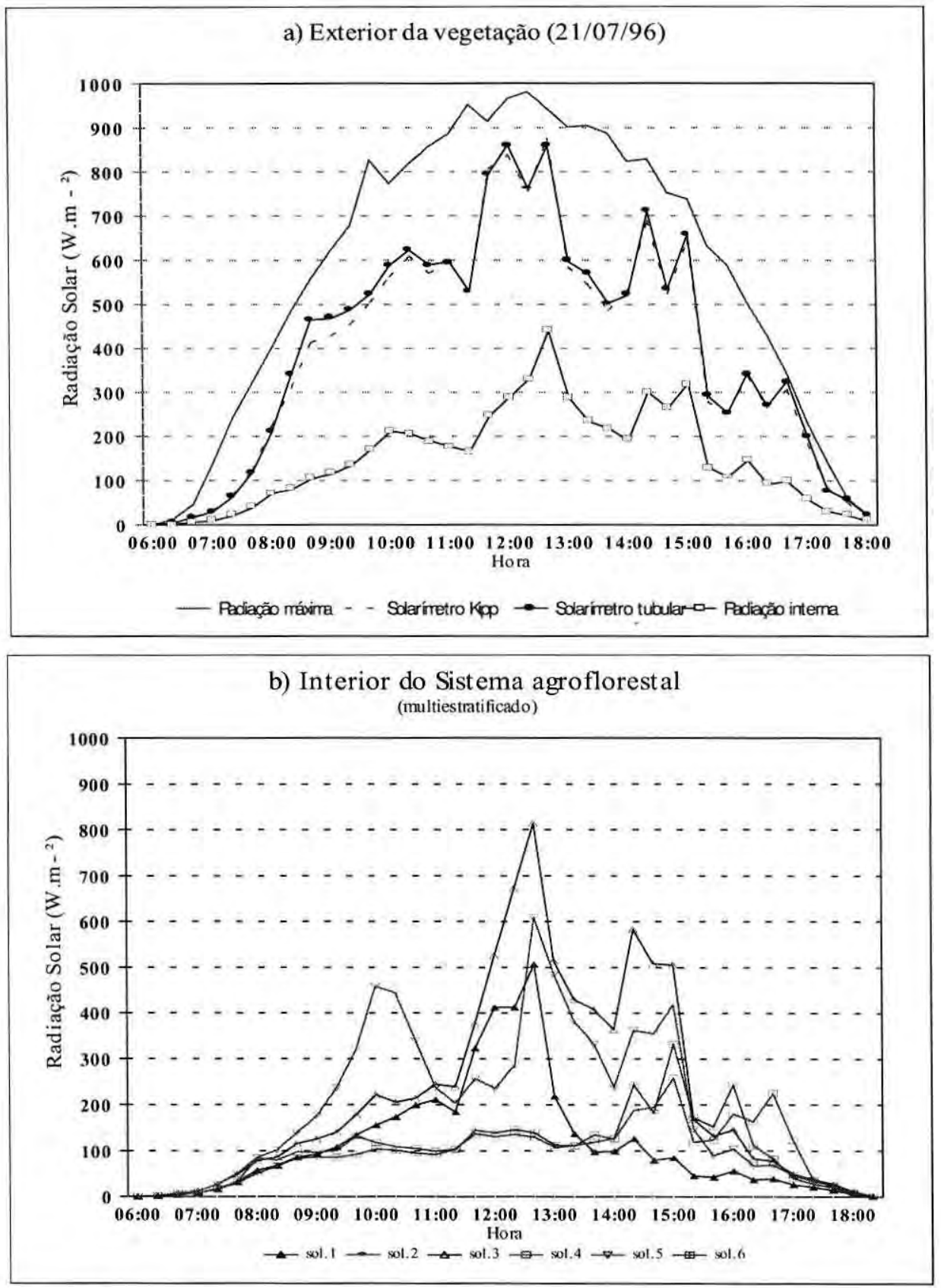

Figura 7. Exemplo comparativo de cursos diurnos de radiação solar em dia de céu claro: a) área externa representando a radiação no topo da vegetação; b) interior do sistema agroflorestal multiestratificado; cada curva de (b) é associada às medições de um solarímetro tubular. A radiação interna mostrada na parte (a) da figura representa a média das curvas da parte (b).. 

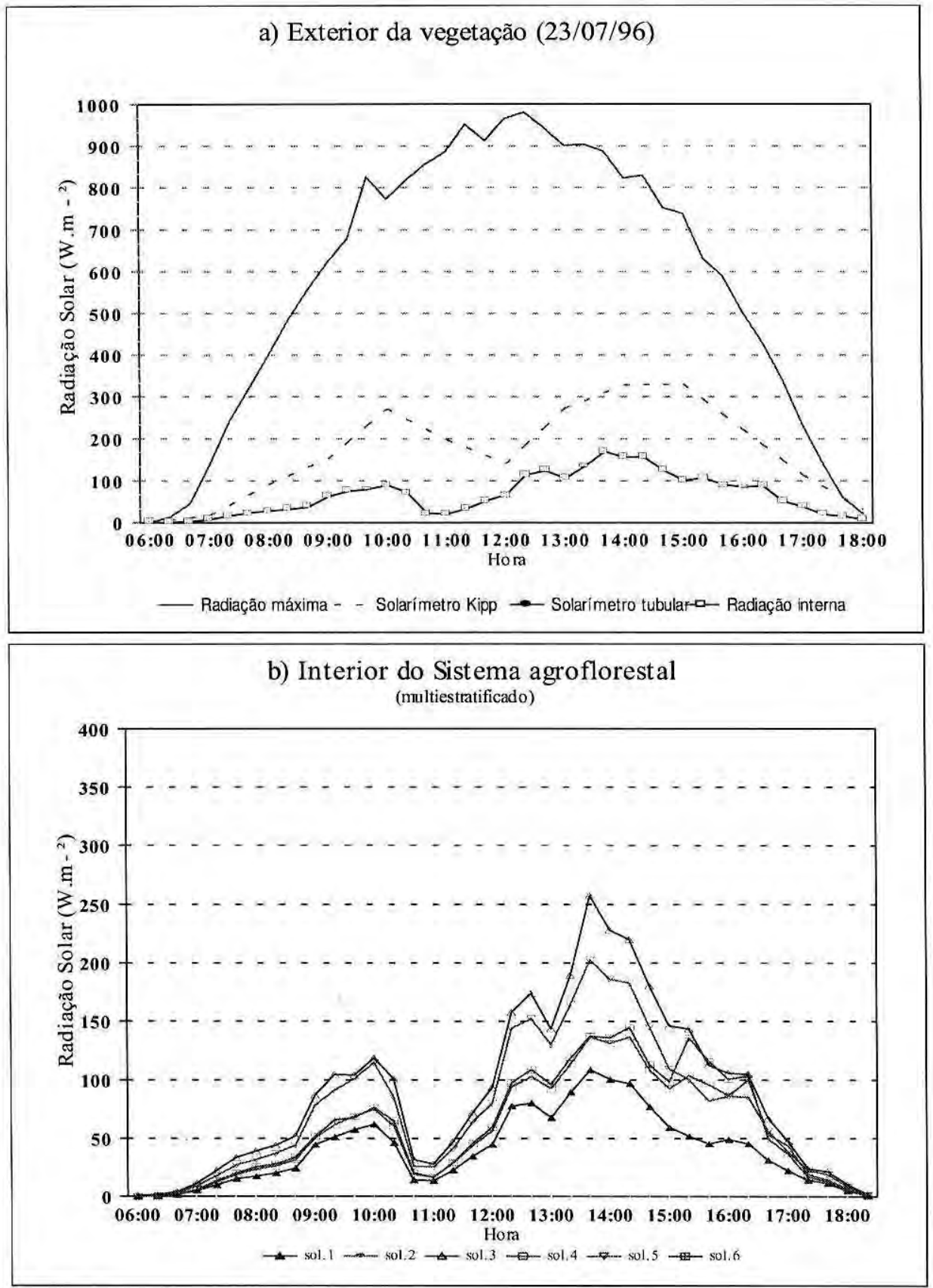

Figura 8. Exemplo comparativo de cursos diurnos de radiação solar em dia de céu encoberto: a) área externa representando a radiação no topo da vegetação; b) interior do sistema agroflorestal multiestratificado. Cada curva de (b) é associada às medições de um solarímetro tubular. A radiação interna mostrada na parte (a) da figura representa a média das curvas da parte (b). 
radiação tem a finalidade de ajustar o modelo físico às condições externas ocorridas em cada caso. Os sensores dispostos sob a cobertura estão sujeitos às peculiaridades do campo radiativo $\mathrm{e}$ da vegetação, no interior da qual se percebe em diferentes direções do hemisfério celeste zonas densamente ocupadas por elementos vegetais entremeadas por manchas de céu por onde penetram a radiação difusa e eventualmente até a radiação direta.

No caso de coberturas vegetais densas, medidas de radiação no topo e no interior da vegetação combinadas com um modelo físico tal como aquele expresso pela equação 2 e um procedimento para gerar a função $\mathrm{A}(\mathrm{z})$ (equação 6) são elementos suficientes para se obter uma estimativa indireta do indice de área foliar da cobertura ( $\mathrm{A}_{0}$ ou IAF).

Das coberturas vegetais em questão, $o$ índice de área foliar $\left(\mathrm{A}_{0}\right)$ foi calculado apenas para a vegetação secundária intacta e para os dois sistemas agroflorestais, por se tratarem de coberturas relativamente densas. Os valores médios do índice de área fo- liar obtidos para as quatro classes de radiação indistintamente dos horários de observação são apresentados na tabela 2 . A vegetação secundária intacta apresentou um valor médio geral de 3,5 ; o sistema agroflorestal com palmeiras um valor de 2,0 ; e o sistema multiestratificado um valor de 1,6. A variação das médias entre as classes é inferior a $5 \%$ da média geral e o desvio padrão em cada classe é crescente a partir do modelo particular puramente difuso (classe I) até o modelo mais complexo com predominância de radiação direta (classes III e IV) para os três tipos de cobertura.

Apesar da vegetação secundária de dez anos ter apresentado índice de área foliar maior que os dos sistemas agroflorestais, o incremento médio anual de IAF é maior nos sistemas agroflorestais de quatro anos, sendo 0,51 no sistema com palmeiras, 0,39 no sistema multiestratificado, e um incremento de 0,35 por ano na vegetação secundária. Isto indica que os sistemas agroflorestais estudados têm um potencial maior para acumular

Tabela 2. IAF calculado para cada classe de radiação e incremento médio anual. Valores entre parênteses representam o desvio padrão.

\begin{tabular}{lcccccc}
\hline & \multicolumn{7}{c}{ IAF médio por classe de radiação } & \multicolumn{2}{c}{ IAF } & Increm. \\
- Tipo de cobertura & I & II & III & IV & Médio & Anual \\
& $(0-25 \%)$ & $(25-50 \%)$ & $(50-75 \%)$ & $(75-100 \%)$ & & de IAF \\
\hline - Vegetação secundária & 3,65 & 3,55 & 3,48 & 3,45 & 3,53 & 0,35 \\
intacta (10 anos) & $(0,11)$ & $(0,27)$ & $(0,64)$ & $(0,59)$ & & \\
\hline - Sistema agroflorestal & 2,04 & 1,96 & 2,05 & 2,10 & 2,04 & 0,51 \\
com palmeiras (4 anos) & $(0,21)$ & $(0,37)$ & $(0,54)$ & $(0,67)$ & & \\
\hline - Sistema agroflorestal & 1,40 & 1,44 & 1,70 & 1,76 & 1,57 & 0,39 \\
multiestratificado (4 anos) & $(0,58)$ & $(0,17)$ & $(0,51)$ & $(0,69)$ & & \\
\hline
\end{tabular}


biomassa do que vegetações secundárias de áreas adjacentes, também estabelecidas em solos degradados.

O sistema agroflorestal dominado por palmeiras tem um IAF maior que o do sistema multiestratificado devido ao fato de que as palmeiras apresentam uma cobertura vegetal contínua originada do pequeno espaçamento de dois metros e uma copa de tamanho já estável a partir do quarto ano, enquanto que no segundo sistema a copa das espécies madeireiras (mogno e teca) ainda estão em fase de desenvolvimento e as copas das espécies arbustivas como araçá não estão cobertas pelas espécies dos estratos superiores. Entretanto, o potencial futuro de acúmulo de biomassa será possivelmente maior no sistema multiestratificado em razão da presença de espécies que atingirão grande porte.

As medidas dos fluxos relativos totais $\left(\alpha_{\mathrm{t}}\right)$ e os resultados obtidos para o indice de área foliar calculado pela metodologia desenvolvida neste trabalho são apresentados em coordenadas polares nas figuras 9 e 10 para a vegetação secundária e sistema agroflorestal com palmeiras, respectivamente. Na parte superior de cada figura, o curso diurno do fluxo total relativo é representado como valor médio das ocorrências dentro de cada uma das classes de radiação, horários e locais específicos no período de observação, e em correspondência na parte inferior representa-se o índice de área foliar resultante.

$\mathrm{Na}$ vegetação secundária intacta (Fig. 9), a curva de fluxos relativos totais associada à Classe I (predominância de radiação difusa) é extremamente regular com padrão circular indicando a constância dos valores medidos durante o dia. A curva representativa de Classe II apresenta irregularidades por volta de 14 horas. Na classe III as discrepâncias são ampliadas e um pico de penetração de radiação ocorre às 14 horas, um exemplo típico de alinhamento numa mesma direção da posição do sol e de vazios da vegetação. Esses eventos indicam claramente a impossibilidade de se estimar o índice de área foliar a partir de medidas de radiação solar isolada no tempo e com forte dominância de radiação direta; nessas condições de radiação (Classes III e IV) somente valores médios de diferentes horários podem produzir um valor médio de indice de área foliar que seja representativo da cobertura. Os índices de área foliar mostrados na parte inferior da figura podem ser interpretados em cada horário e classe como uma curva simétrica a dos fluxos relativos com oscilações atenuadas. Maiores fluxos relativos produzem menores valores de indice de área foliar.

No sistema agroflorestal (Fig. 10) as curvas de fluxos relativos são irregulares e flutuações aparecem em todas as classes de radiação; entretanto, a partir das 8:00h as curvas das classes I e II aproximam-se a uma forma circular, em contraste à classe III que é bastante variável no periodo.

Os desvios das estimativas do IAF apresentados no presente trabalho (Tab. 2) são inferiores aqueles obtidos por Honzák et al. (1996) e essas diferenças podem ser possivelmente atribuidas às restrições nas condições e horários de medidas impostas pelo tipo de equipamentos utilizado por esses autores (ceptometers e fotografias hemisféricas). 


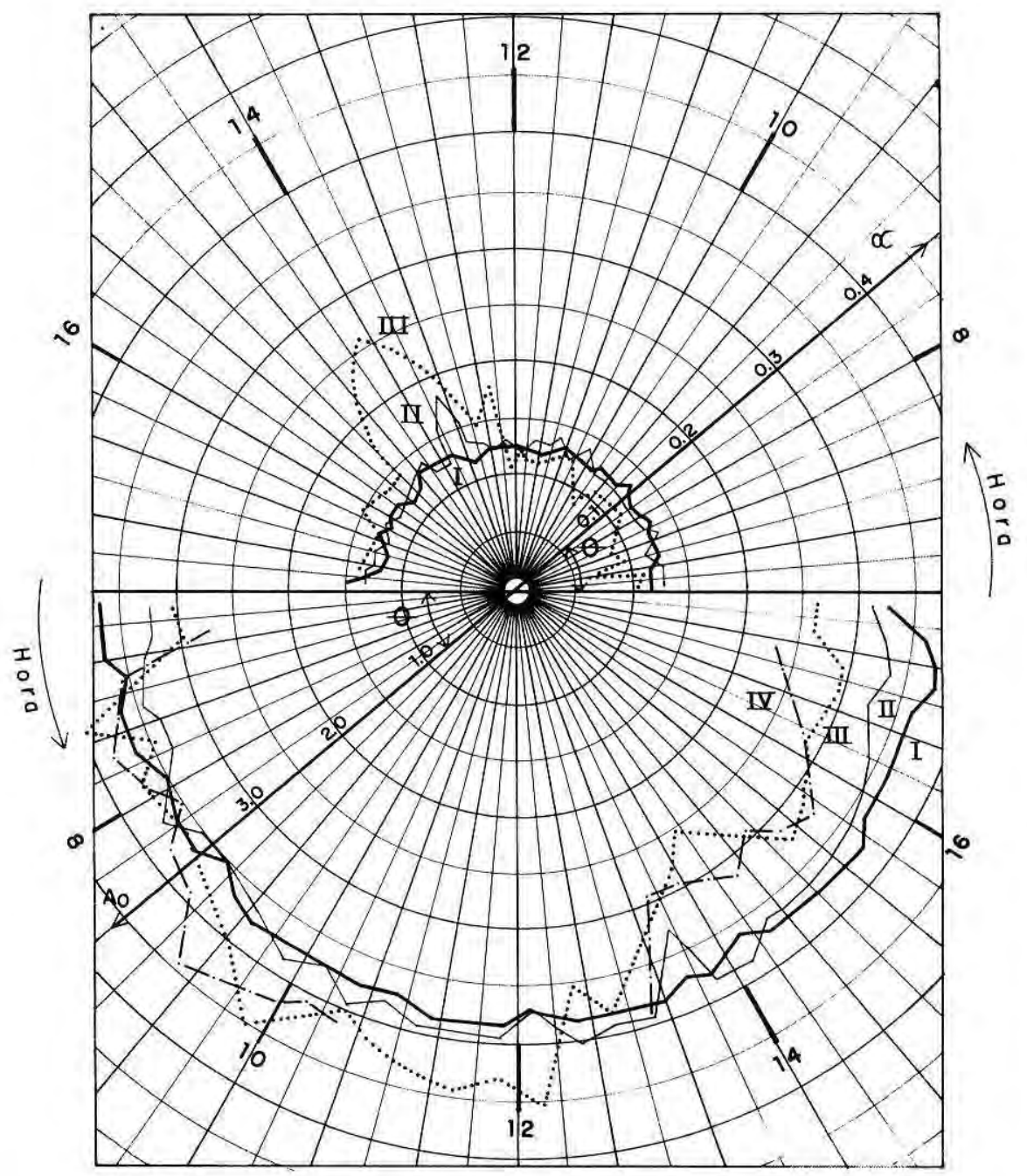

Figura 9. Fluxos relativos - á (parte superior da figura) e IAF - $\mathrm{A}_{0}$ (parte inferior) calculac para vegetação secundária intacta. 


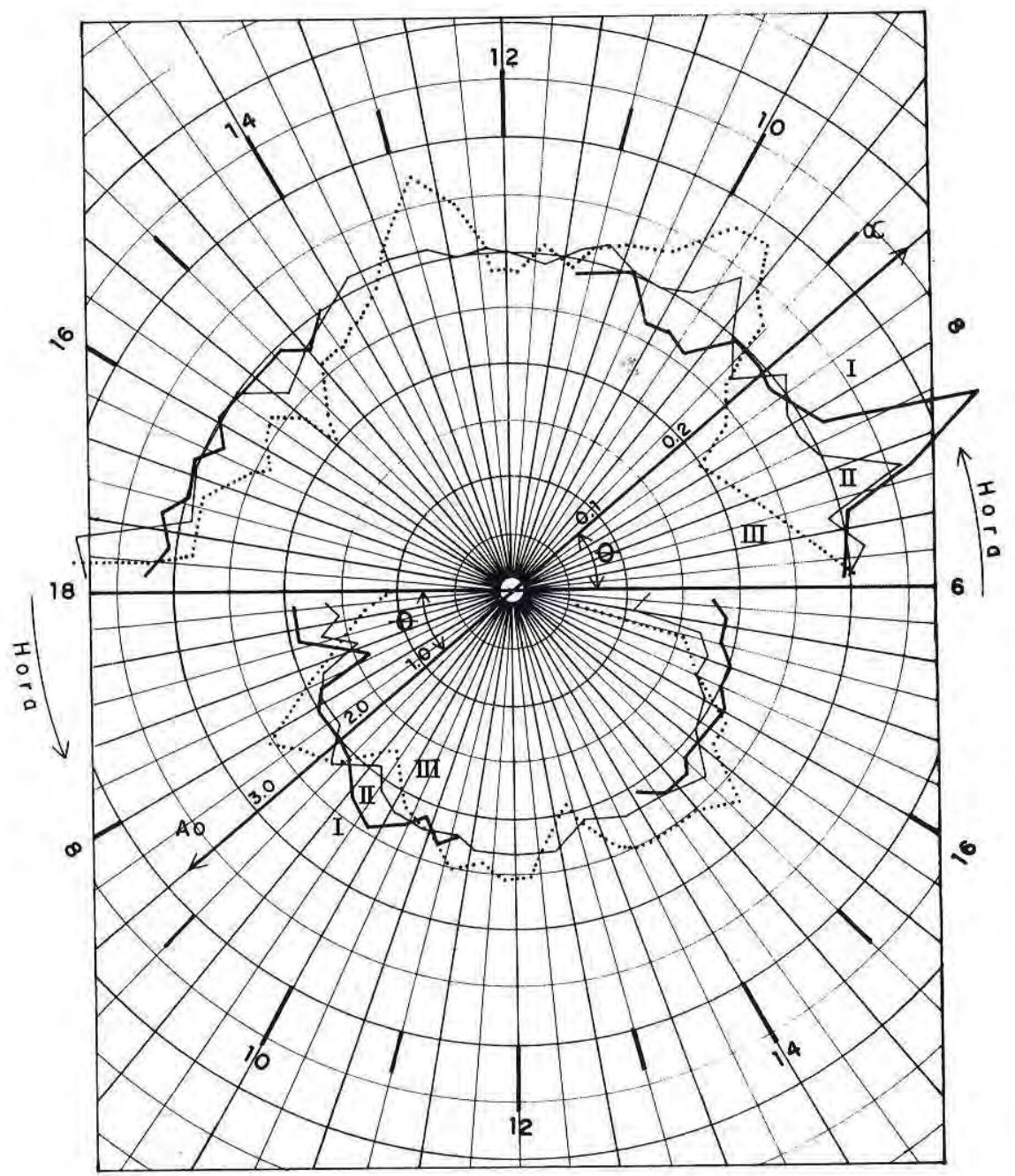

Figura 10. HIuxos relativos - a (parte superior da tigura) e IAF - $\mathrm{A}_{0}$ (parte interior) calculado's para o sistema agroflorestal com palmeiras. 
Uma característica do presente estudo é o cálculo do IAF médio a partir de medidas distribuídas em todo o período diurno, incorporando assim diferentes zonas de amostragem da vegetação na composição final do índice.

\section{CONCLUSÃO}

O método de inversão do modelo de radiação para estimar o indice de área foliar de coberturas vegetais produz em geral valores de IAF convergentes entre as classes de radiação adotadas com desvios crescentes para as situações em que predomina a radiação direta. As estimativas do IAF são mais estáveis para os dias com domínio de luz difusa. A radiação difusa é mais apropriada para inferir características de cobertura vegetal, pois nela não existe a influência preferencial de um ângulo de incidência (ausência de radiação direta).

A grande dispersão encontrada nas estimativas de IAF para o sistema agroflorestal multiestratificado indica a necessidade de uma abordagem específica ao problema de amostragem de radiação e o desenvolvimento de modelos físicos mais adequados para o tratamento da interação da radiação em vegetação não contínua.

$\mathrm{O}$ índice de área foliar apresenta-se com valores decrescentes para a vegetação secundária, sistema agroflorestal com palmeiras e sistema multiestratificado; entretanto o incremento médio anual de IAF é maior nos sistemas agroflorestais, indicando uma tendência e um bom potencial desses sistemas para acumular biomassa.

\section{AGRADECIMENTOS}

Os autores agradecem aos técnicos da Coordenação de Pesquisas em Geociências do INPA: Afonso Ligório da Mota, Hermes Braga Xavier, Jauapery Neves Pereira Júnior, Sérgio Magno Valério de Souza e Valdelice Pereira da Silva; aos técnicos da Embrapa Rubenildo Silva e Iracino Bonfim pela ajuda na preparação e instalação dos sistemas de medidas; ao BSc Francis Wagner pela ajuda na instalação e coleta dos dados; ao Dr. Gotz Schroth pelo empréstimo dos solarimetros tubulares, Este estudo se insere no Projeto de Pesquisa "Recuperação de pastagens abandonadas ou degradadas através de sistemas agroflorestais", financiado pelo PP-G7.

\section{Bibliografia citada}

Abramowitz, M.; Stegun, I. 1970. A Handbook of Mathematical Functions. Dover Publications, Washington D.C. 1046 p.

Andrieu, B.; Baret, F. 1993. Indirects methods of estimating crop structure from optical measurements. In: Varlet-Grancher, C; Bonhomme, R.; Sinoquet, H. (eds.). Crop structure and Light Microclimate. 285-322.

Honzák, M.; Lucas, R. M.; Amaral. I.; Curran, P. J.; Foody, G. M.; Amaral, S., 1996 Estimation of the leaf area index and total biomass of tropical regenerating forests: comparison of methodologies, In: Gash, J.H.C.; Nobre, C.A.; Roberts, J.M.; Victoria, R. L.(eds.) Amazonian deforestation and Climate edited by, Institute of Hydrology, UK: 365-381.

McWilliam, A. L. C.; Roberts, J. M.; Cabral, O. M. R.; Leitão, M. V. B. R.; Costa, A. C. L.; Maitelli, G. T; ZamparonI, C. A. G. P. 1993. Leaf area index and above ground biomass of terra firme rain forest and adjacent clearings in Amazonia. Functional Ecology, 7: 210-217. 
Marques Filho, A.O. 1992 Modèles des transferts radiatifs à l'interrieur des couverts végétaux - les solutions analytiques Acta Amazonica, 22(4): 541-565.

Marques Filho, A.O. 1997 Regime de radiação solar e características da vegetação Modelos de inversão, Acta Amazonica, 27(2): 119-134.

Myneni, R.R.; Ross, J.; Asrar, G. 1989. - A Review on the Theory of Photon Transport in Plant Canopies. Agricultural and Forest Meteorology 45: 1-153.

Nilson, T. 1971. A theoretical analysis of the frequency of gaps in plant stands, Agricultural and Forest Meteorology 8: 25-38.

Roberts, J. M.; Cabral, O. M. R.; Costa, J. P.; McWilliam, A. L. C.; Sá, T. D. A. 1996. Leaf area index biomass and physiological responses in Amazonian forest and pasture. In: Gash, J.H.C.; Nobre, C.A.; Roberts, J.M; Victoria R. L. (Eds). Amazonian deforestation and Climate. Institute of Hydrology, UK. p. 287-306.
Ross, J. 1981. The Radiation Regime and the Architecture of Plant Stands. Dr. W. Junk Publ., The Netherlands.

Souza, S. G. A. de; Matos, J. C. de S.; Wandelli, E. V.; Perin, R. e Fernandes, E. C. M. 1996. Avaliação de sistemas agroflorestais em áreas de pastagens degradadas e/ou abandonadas da Amazōnia Ocidental. Anais do Forest 96. Belo Horizonte.

Wandelli, E.V.; Perin, R.; Matos, J. C. de S e Fernandes, E. C. M., 1997. Sistemas agroflorestais: uma alternativa para recuperação de áreas de pastagens degradadas. Anais do III Simpósio Nacional de Recuperação de Areas Degradadas, Ouro Preto.

Welles, J. M.; Norman, J. M. 1991. Instrument for indirect measurement for canopy architecture, Agronomy Journal, 53; 818-825. 